\title{
Prevention of osteoporosis and osteoporotic fractures in postmenopausal women: recommendation statement from the Canadian Task Force on Preventive Health Care
}

\section{Angela M. Cheung, Denice S. Feig, Moira Kapral, Natalia Diaz-Granados, Sylvie Dodin, and the Canadian Task Force on Preventive Health Care}

A longer version of this article is available online at www.cmaj.ca

\section{Recommendations (see also Fig. 1)}

- The Canadian Task Force on Preventive Health Care concludes that there is fair evidence to recommend screening postmenopausal women to prevent fragility fractures (no or low trauma fractures) (grade B recommendation). Although there is no direct evidence that screening reduces fractures, there is good evidence that screening is effective in identifying postmenopausal women with low bone mineral density and that treating osteoporosis can reduce the risk of fractures in this population (grade A recommendation).

- For women who screen positive for osteoporosis, there is good to fair evidence that therapy with alendronate, risedronate or raloxifene prevents osteoporotic fractures (grade $\mathrm{A}$ to $\mathrm{B}$ recommendation).

- For women with severe osteoporosis (osteoporosis plus at least 1 fragility fracture), there is good to fair evidence to recommend the use of alendronate, risedronate, parathyroid hormone (limited duration), raloxifene, etidronate and oral pamidronate therapy (grade A to B recommendation). If none of these drugs is tolerated, hormone replacement therapy (HRT) or calcitonin can be considered. (In a recent position statement, the task force recommended against combined estrogen-progestin therapy as well as unopposed estrogen therapy for the primary prevention of chronic diseases [grade D recommendation]..$^{3}$ )

- For women without documented osteoporosis, there is fair evidence that calcium and vitamin D supplementation alone prevents osteoporotic fractures (grade B recommendation). There is fair evidence that combined estrogen-progestin therapy decreases the incidence of total, hip and nonvertebral fractures; however, for most women the risks may outweigh the benefits (grade D recommendation). (As noted above, the task force recently recommended against HRT for the primary prevention of chronic diseases [grade D recommendation]. ${ }^{3}$ )

Osteoporosis, the main clinical consequence of which is osteoporotic fracture, affects 1 in 6 Canadian women over the age of $50 .{ }^{1}$ About $40 \%$ of white women 50 years of age in Canada will have an osteoporotic fracture during their remaining lifetime:
$15.6 \%$ will experience a vertebral fracture, $16.0 \%$ a wrist fracture and $17.5 \%$ a hip fracture. ${ }^{2}$

The recommendations in this statement apply to most postmenopausal women in the general population, including those who have late menarche, early menopause, low calcium intake, low physical activity, high alcohol or caffeine intake, low body weight, a family history of osteoporosis or osteoporotic fractures or a history of hyperthyroidism or who are smokers. However, they do not apply to women who have specific conditions that predispose them to significant increased risk of fractures, including women taking steroids, those with hyperparathyroidism and those in nursing homes. These recommendations are meant to guide physicians in their discussions with their postmenopausal patients, as each individual woman may have unique risks and preferences. The recommended age for initiation of screening is based on the prevalence of osteoporosis and fractures among postmenopausal women in the different age groups.

Our recommendations are based on fracture data rather than on bone mineral density (BMD) data, since we do not know how short-term BMD differences translate into longterm fracture outcomes, especially among women without osteoporosis. A unique feature of our guideline is that we do not recommend using drug therapy for the primary prevention of osteoporosis, especially in young postmenopausal women. More than $45 \%$ of postmenopausal women have osteopenia. ${ }^{1}$ The fracture risk for most of these women is low. Because risk of fracture increases with age, it may be reasonable to consider prescribing 
drug therapy for women who are 65 years or older and who have a T score below -2.0.

\section{Recommendations of others}

The US Preventive Services Task Force recommends that women 65 years or older be screened routinely for osteoporosis and that those at increased risk of osteoporotic fractures (see Box 1) begin screening at age 60 (grade B recommendation). ${ }^{4}$

The recent Osteoporosis Society of Canada guidelines recommend screening with DEXA (dual energy $\mathrm{x}$-ray absortiometry) for postmenopausal women who have 1 major and 2 minor clinical factors (Box 1) or those 65 years and older. ${ }^{5}$ They also recommend using bisphosphonates and raloxifene as first-line therapy for the prevention and treatment of osteoporosis, HRT as first-line therapy for the prevention of osteoporosis and as second-line therapy for the treatment of osteoporosis (although risks may outweigh benefits) and nasal calcitonin therapy as second-line therapy for the treatment of osteoporosis. In addition, they recommend using parathyroid hor- mone as first-line therapy for the treatment of severe osteoporosis.

The Society of Obstetricians and Gynaecologists of Canada (SOGC) guidelines, published before the release of the $\mathrm{Wo}_{\mathrm{O}}$ men's Health Initiative (WHI) results, recommend using HRT, raloxifene and the bisphosphonates (all grade I recommendations) as well as calcium and vitamin D supplementation and exercise (all grade II recommendations) for the primary prevention of osteoporosis. They also recommend raloxifene, alendronate, risedronate, calcitonin and combination therapy (all

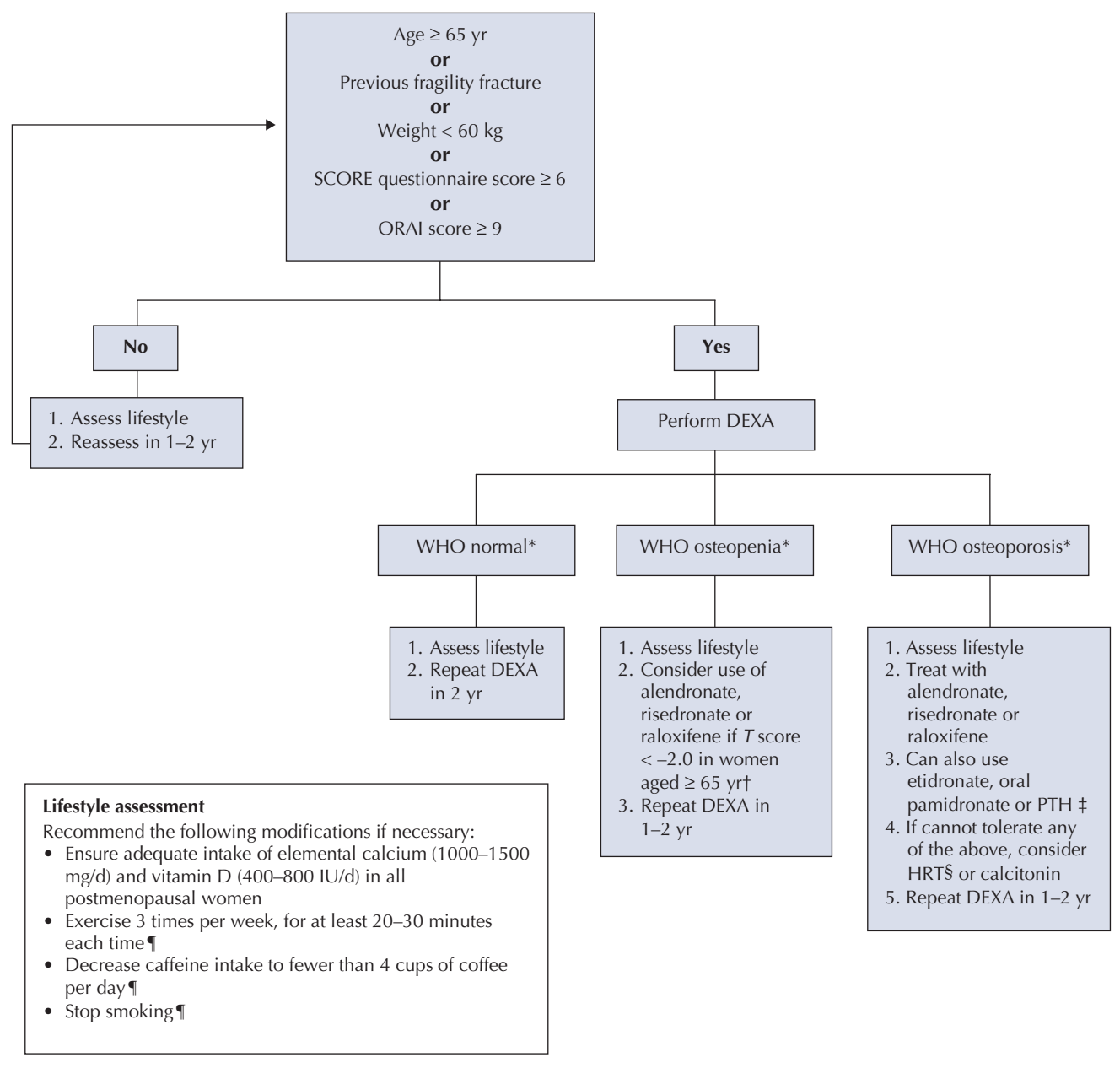

Fig. 1: Recommendations of the Canadian Task Force on Preventive Health Care for the prevention of osteoporotic fractures in postmenopausal women. This algorithm excludes women with secondary osteoporosis (e.g., those who have hyperparathyroidism or are taking steroids). ${ }^{*}$ World Health Organization $(\mathrm{WHO})$ definitions: normal $=\mathrm{T}$ score $\geq-1.0$; osteopenia $=\mathrm{T}$ score $<-1.0$ and $>-2.5$; osteoporosis $=\mathrm{T}$ score $\leq-2.5$, where the $\mathrm{T}$ score is the standard deviation above or below the mean bone mineral density for young adults. †Published data have not shown any reduction in clinical fracture in this group of postmenopausal women. ‡Evidence to support the use of these medications is limited to postmenopausal women with osteoporosis and prevalent fractures. $\S$ For most postmenopausal women without menopausal symptoms, the risks may outweigh the benefits. I These recommendations are not based on fracture data. DEXA = dual energy x-ray absortiometry. SCORE and ORAI are two risk assessment tools (available online). $\mathrm{PTH}=$ parathyroid hormone. 
grade I recommendations) and HRT and etidronate (grade II recommendations) for the treatment of osteoporosis. Since publication of the WHI results, the SOGC has revised its recommendation on combined estrogen-progestin therapy, stating that the overall risks may outweigh the benefits for postmenopausal women without menopausal symptoms and that other therapies should be considered first. ${ }^{6}$

Box 1: Risk factors for osteoporotic fractures in postmenopausal women

Major

- Age $\geq 65 \mathrm{yr}$

- Vertebral compression fracture

- Fragility fracture after age $40 \mathrm{yr}$

- Family history of osteoporotic fracture (especially hip fracture in mother)

- Systemic glucocorticoid therapy $\geq 3$ mo

- Malabsorption syndrome

- Primary hyperparathyroidism

- Propensity to fall

- Appearance of osteopenia on radiograph

- Hypogonadism and early menopause $(<45 \mathrm{yr})$

Minor

- Rheumatoid arthritis

- History of clinical hyperthyroidism

- Long-term anticonvulsant therapy

- Weight loss $>10 \%$ of body weight at age $25 \mathrm{yr}$

- Weight $<57 \mathrm{~kg}$

- Smoking

- Excess alcohol intake

- Excess caffeine intake

- Low dietary calcium intake

- Long-term heparin therapy

These risk factors were taken from the Osteoporosis Society of Canada 2002 clinical practice guidelines. Addition risk factors for osteoporotic fractures include: being Caucasian or Asian, not on HRT, having low BMI, low physical activity, impaired vision, dementia, recent falls, poor health and being frail.
Angela Cheung is Director of the Osteoporosis Program and Associate Director of the Women's Health Program, University Health Network, and is Assistant Professor, Faculty of Medicine, University of Toronto, Toronto, Ont. Denice Feig, a task force member, is at Mount Sinai Hospital and is Assistant Professor in the Departments of Medicine, of Obstetrics and Gynecology, and of Health Policy Management and Evaluation, University of Toronto. Moira Kapral is with the Department of Medicine, the Division of General Internal Medicine and the Women's Health Program, University Health Network, and the Institute of Clinical Evaluative Sciences, Toronto, Ont. Natalia Diaz-Granados was a University of Toronto Master's student in epidemiology and worked as a research assistant in the University Health Network/Mount Sinai Osteoporosis Program, Department of Medicine, University of Toronto. Sylvie Dodin is with the Departments of Obstetrics and Gynaecology, Laval University, Quebec City, and University of Sherbrooke, Sherbrooke, Que.

Competing interests: Angela Cheung has received honoraria to participate in CME events partially or fully supported by Eli Lilly, Merck, Proctor \& Gamble, Aventis and Novartis; these companies have also contributed unrestricted educational grants in support of Toronto City-wide Osteoporosis Rounds, which Angela Cheung chairs. Natalia DiazGranados received a University Health Network/Merck Osteoporosis Scholarship in support of her Master's degree in epidemiology and her thesis work on predictors of osteoporosis in men. No competing interests declared for Moira Kapral, Sylvie Dodin or the members of the Canadian Task Force on Preventive Health Care.

Contributors: Angela Cheung authored the original systematic evidence review, drafted the current article and made subsequent revisions. Denice Feig, Moira Kapral, Natalia Diaz-Granados and Sylvie Dodin coauthored the original systematic evidence review, critically reviewed the current article and reviewed subsequent revisions. The Canadian Task Force on Preventive Health Care critically reviewed the evidence and developed the recommendations according to its methodology and consensus development process.

\section{References}

1. Tenenhouse A, Joseph L, Kreiger N, Poliquin S, Murray TM, Blondeau L, et al. Estimation of the prevalence of low bone density in Canadian women and men using a population-specific DXA reference standard: the Canadian Multicentre Osteoporosis Study (CaMOS). Osteoporos Int 2000;11:897-904.

2. Melton LJ, Chrischilles EA, Cooper C, Lane AW, Riggs BL. Perspective: how many women have osteoporosis. 7 Bone Miner Res 1992;7:1005-10.

3. Wathen CN, Feig DS, Feightner JW, Abramson BL, Cheung AM, Canadian Task Force on Preventive Health Care. Hormone replacement therapy for the primary prevention of chronic diseases: recommendation statement from the Canadian Task Force on Preventive Health Care. CMA7 2004;170(10):1535-7.

4. US Preventive Services Task Force. Screening for osteoporosis in postmenopausal women. Ann Intern Med 2002;137:526-8.

5. Khan AA, Brown JP, Kendler DL, Leslie WD, Lentle BC, Lewiecki EM, et al. The 2002 Canadian bone densitometry recommendations: take-home messages. CMA7 2002;167(10):1141-5.

6. Society of Obstetricians and Gynaecologists of Canada. The Canadian Consensus Conference on Menopause and Osteoporosis - 2002 update [SOGC guideline no 108]. Ottawa: The Society; 2002. Available: http://sogc.medical.org/SOGCnet /sogc_docs/common/guide/pdfs/osteo Meno.pdf (accessed 2004 Apr 22).

\section{Correspondence to: Canadian}

Task Force on Preventive Health

Care, 117-100 Collip Circle,

London ON N6G 4X8; fax 519

858-5112; ctf@ctfphc.org

\section{Members of the Canadian Task Force on Preventive Health Care}

Chair: Dr. John W. Feightner, Professor, Department of Family Medicine, The University of Western Ontario, London, Ont. Vice-Chair: Dr. Harriet MacMillan, Associate Professor, Departments of Psychiatry and Behavioural Neurosciences and of Pediatrics, Canadian Centre for Studies of Children at Risk, McMaster University, Hamilton, Ont. Members: Drs. Paul Bessette, Professeur titulaire, Département d'obstétrique-gynécologie, Université de Sherbrooke, Sherbrooke, Que.; R. Wayne Elford, Professor Emeritus, Department of Family Medicine, University of Calgary, Calgary, Alta.; Denice S. Feig, Assistant Professor, Departments of Medicine, of Obstetrics and Gynecology, and of Health Policy Management and Evaluation, University of Toronto, Toronto, Ont.; Joanne M. Langley, Associate Professor, Departments of Pediatrics and of Community Health and Epidemiology, Dalhousie University, Halifax, NS; Valerie Palda, Assistant Professor, Department of Medicine, University of Toronto, Toronto, Ont.; Christopher Patterson, Professor, Division of Geriatric Medicine, Department of Medicine, McMaster University, Hamilton, Ont.; and Bruce A. Reeder, Professor, Department of Community Health and Epidemiology, University of Saskatchewan, Saskatoon, Sask. Resource people: Ruth Walton, Research Associate, and Jana Fear, Research Assistant, Canadian Task Force on Preventive Health Care, Department of Family Medicine, The University of Western Ontario, London, Ont. 